\title{
Study of Factors Affecting Medical Incident: 1. Dispensing
}

\author{
Yuka Miyachi, Chika Nakayama, Kazuyo Nagashiba, Kou Kinoshita, Masayuki Takeuchi, \\ Masafumi Ohnishi, Hiroko Saito, Taeyuki Oshima
}

College of Pharmacy, Kinjo Gakuin University, Moriyama-ku, Nagoya, Japan

Email: y-miyachi@kinjo-u.ac.jp

How to cite this paper: Miyachi, Y., Nakayama, C., Nagashiba, K., Kinoshita, K., Takeuchi, M., Ohnishi, M., Saito, H. and Oshima, T. (2018) Study of Factors Affecting Medical Incident: 1 . Dispensing. Pharmacology \& Pharmacy, 9, 527-535. https://doi.org/10.4236/pp.2018.912041

Received: November 12, 2018 Accepted: December 17, 2018 Published: December 20, 2018

Copyright $\odot 2018$ by authors and Scientific Research Publishing Inc. This work is licensed under the Creative Commons Attribution International License (CC BY 4.0).

http://creativecommons.org/licenses/by/4.0/

\begin{abstract}
In recent years, medical institutions have taken a variety of measures to prevent medical incident. In addition, progress has been made toward the development of a fully automated system for the purpose of medicine dispensing. However, automating the dispensing, or having it replaced by artificial intelligence (AI) will not, eradicate human error. Thus, measures against human error will continue to serve as an important topic. Therefore, hospitals are required to improve the efficiency of the pharmacy department. For these purposes, attention has now shifted to Supply Processing and Distribution (SPD). In this study, we measured for the gaze of the pharmacist and SPD, and examined the factors affecting dispensing error; moreover, we examined prevention of the human error. In the results of the eye tracking, SPD members tended to spend a greater number of gaze time and gaze counts, for each medicine, on "medicines" and "picking lists," than pharmacists. On the other hand, when pharmacists picking medicines, they performed various work operations in parallel, such as checking the prescription and looking the next shelf location. It was conjectured that SPD members had more clearly defined items to check when picking, compared to pharmacists. This may have possibly led to a lower chance of dispensing errors being introduced by SPD members. These results suggest that the process of selection is not a mandatory requirement of pharmacists during the action of dispensing. Instead, SPD members, pharmacy assistants, or automatic dispensing devices could serve as substitutes for picking. It is suggested that pharmacists should spend more time and effort on prescription inspection, medicines checking and dosing operations.
\end{abstract}

\section{Keywords}

Dispensing Error, Eye Tracking, Pharmacist, Supply Processing and Distribution 


\section{Introduction}

The Japan Council for Quality Health Care (JQ) reports that approximately 7\% of medical incident, and approximately $40.4 \%$ of error events that occur in hospitals, involve pharmaceuticals [1]. For this reason, medical institutions have taken a variety of measures to prevent medical incident. In recent years, progress has been made toward the development of a fully automated system for the purpose of medicine dispensing. In addition, dispensing support systems using mobile information terminals, and the like, have also been employed as measures to prevent dispensing errors [2]. Automating the dispensing, or having it replaced by artificial intelligence (AI) will not, however, eradicate human error. Thus, measures against human error will continue to serve as an important topic. Human error refers to a situation where: 1) a certain behavior is portrayed by a person, 2) that is outside the specific tolerance limit, and 3) that cannot be treated as a mere coincidence. Accordingly, one's behavioral mechanism is considered important in the understanding of human error [3]. Revisions of the medical fee system in the 2012 fiscal year in Japan provided additional fees for the ward operations of the pharmacist [4]. Pharmacists are required to be stationed in their respective unit for at least 20 hours per week, and to be active members of the medical team [5] [6]. Therefore, attention has now shifted to SPD (Supply Processing and Distribution). SPD refers to the centralized management of all items used in a hospital, as well as the organizational and structural centralization of item storage, central materials rooms, and supply departments. SPD is also intended to improve operational efficiency, and to allow specialists to concentrate on their work [7] [8]. SPD member of pharmacy handles inventory management and stock level maintenance. Depending on the hospital, internal transport, refilling automatic injection dispensing systems, and work selection, may also be handled by SPD member. It has been predicted that the use of SPD will continue to increase. However, when the picking of medicines is performed by individuals that are not qualified, and lack the pharmaceutical knowledge required, this could lead to the risk of dispensing errors.

Very few reports have objectively evaluated pharmacists and SPD picking of medicine, from the perspective of medical incident. To consider factors that induce dispensing errors in hospital pharmacy, we focused on eye tracking and pupil diameter change. Eye tracking entails tracking the movements of a person's gaze. By performing such eye tracking, we can reveal where one's focus lies when acting. Changes in pupil diameter occur due to involuntary operations of the pupillary sphincter and pupillary dilator, due to autonomous nerves. Pupillary dilation is thought to occur when muscles contract as the brain becomes active. Therefore, pupil diameter is expected to provide information related to concentration and the like [9] [10].

In this research, we investigated staffs who caused dispensing errors in Aichi Medical University Hospital. We also considered the factors leading to medical incident using an eye tracking technology, capable of measuring a person's eye movement. 


\section{Method}

\subsection{Investigation of Error Events}

We investigated the dispensing error of pharmacist or SPD member, in the Department of Pharmacy at the Aichi Medical University Hospital. This hospital is a general hospital of 900 beds. 78 pharmacists and 12 SPD members are enrolled in this hospital. The investigation was conducted from July 1 to 31,2018 . We examined the number of incorrect counts and the number of missed dispensing during the process of picking.

\subsection{Eye Tracking}

\subsubsection{Subjects}

The subjects were 5 pharmacists and 4 SPD members working at the Aichi Medical University Hospital. The pharmacist's average age was $29.4 \pm 4.2$ years old (one male and 4 female, their incumbency 2 - 15 years). The SPD member's average age was $32.5 \pm 5.0$ years old (all female, their incumbency less than a year).

\subsubsection{Measurement Method}

We conducted an eye tracking study to evaluate the picking by the subjects, during their regular work activity. The number of medicines and their shelf locations differed for each prescription. Subjects' gaze was tracked using Tobii Pro glasses 2 (Tobii Technology K.K. Figure 1).

Pharmacists made picking based on prescriptions, while SPD members chose from picking lists. The prescriptions displayed patient background, medicine name, administration and dosages, total dose, shelf locations, and previous prescription details. The picking lists displayed shelf locations, medicine name, and total dose. The subjects' eye movements, gaze time, pupil diameter and field of vision image data were collected and analyzed.

The analysis of the image records was performed using Tobii Pro Lab (Tobii Technology K.K.) and Windows Live Movie Maker. Figure 2 shows the gaze flow from Tobii Pro Lab.

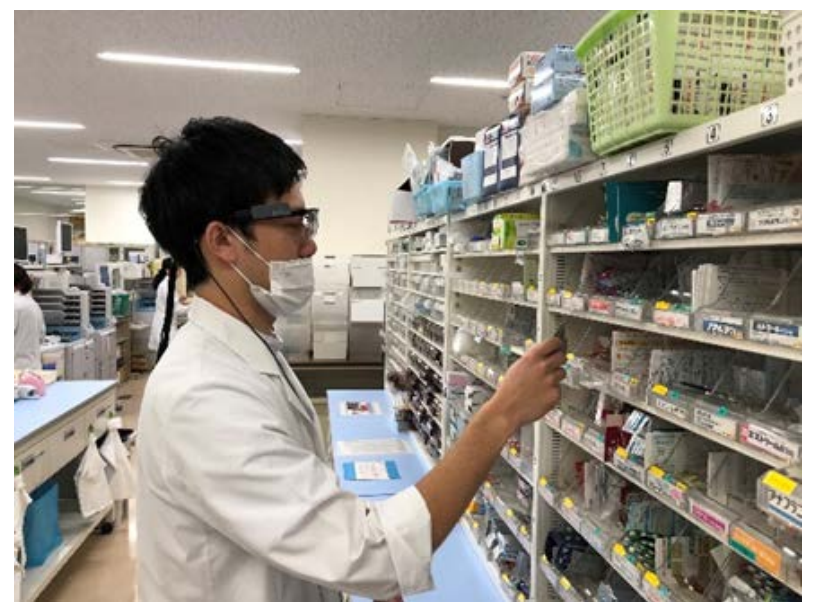

Figure 1. Tobii pro glass 2. 


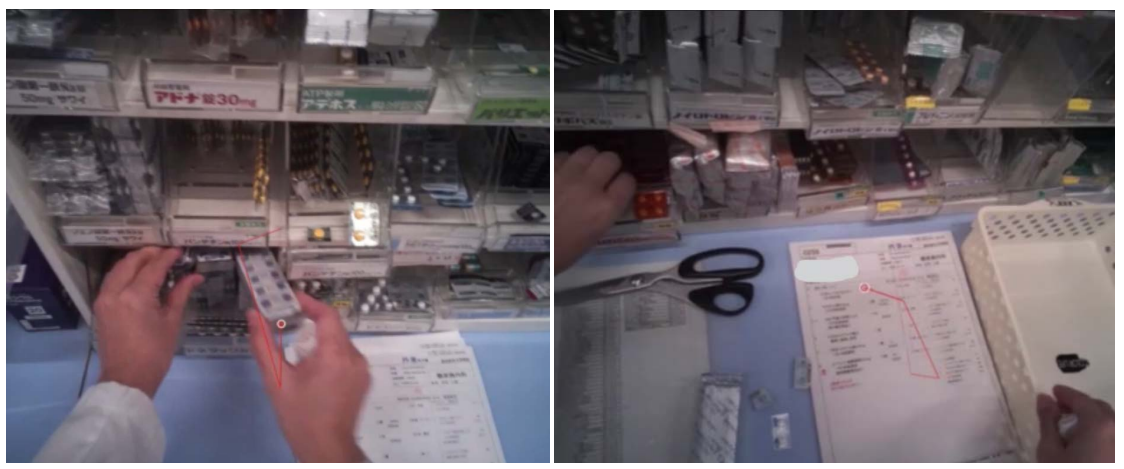

Figure 2. The gaze flow from Tobii Pro Lab.

\subsubsection{Gaze Points}

The gaze points used shelf, medicines, prescriptions (patient background, medicine name, administration and dosage, total dose and shelf location) or picking list (shelf location, medicine name, total dose), and others (inner bag, signature, et al.).

\subsubsection{Pupil Diameter}

Actions during the entire picking process were divided into 6 actions. The actions included: looking at the prescription (picking list), picking, putting medicines in the inner bag, looking at shelves, moving while looking at the prescription (picking list), and moving. The left and right pupil diameters were averaged, and the mean pupil diameter for each behavior as divided was computed. The formula used to calculate the rate of change from the mean value was as follows.

The rate of change $(\%)=($ Mean pupil diameter for each behavior as divided-Mean pupil diameter for the entire prescription)/(Mean pupil diameter for the entire prescription) $\times 100$.

\subsubsection{Ethics Statements}

This study is approved by the Kinjo Gakuin University Ethical Review Board (No. H17015).

\section{Result}

\subsection{Investigation of Error Events}

Over the period of the investigation, an average of $820.6 \pm 56.5$ prescriptions were processed each day. The pharmacists picked 11,323 prescriptions during the period. And, the inspection discovered 194 counting errors and 61 unfilled picking, resulting in error event rate of approximately $2.3 \%$. Conversely, the SPD members picked 6381 picking lists and the inspection discovered 51 counting errors and 20 unfilled picking. The error event rate was approximately $1.1 \%$, a rate approximately half that of pharmacists.

\subsection{Eye Tracking}

\subsubsection{Work Content and Work Time}

Pharmacists picked $5.8 \pm 1.0$ prescriptions per person, while the SPD members 
picked $6.5 \pm 0.9$ picking lists per person. Pharmacists picked $15.6 \pm 5.0$ medicines, while SPD members picked $19.8 \pm 8.2$ medicines. The picking time per medicine was $14.9 \pm 5.9(\mathrm{sec})$ and $19.8 \pm 5.1(\mathrm{sec})$ for pharmacists and SPD members, respectively. The internal rules in the Department of Pharmacy of the hospital stipulate that "SPD members shall put each medicine in an inner bag" and that "Pharmacists shall put medicines in an inner bag if they have the same administration." Other than placing medicines in inner bags, the work performed by pharmacists and SPD members was the same.

\subsubsection{Gaze Rate and Gaze Time}

Table 1 shows the gaze rate during picking. The gaze rate is defined as the proportion of time that the subject spent gazing on the item, based on the entire work performed. Pharmacists tended to have higher gaze rates for "shelf" and "prescriptions". The total of "shelf location" and "total dose" for SPD members was $13.1 \% \pm 6.8 \%$; this represented a higher gaze rate than that of the pharmacists. The gaze rates of the pharmacists and SPD members on medicines, were approximately $45 \%$, and equal between the two subject groups.

Table 2 shows the number of gaze events per medicine. SPD members showed the tendency to gaze more frequently on "medicines" and "picking list". The total number of gaze placed on "shelf location" and "total dose" was $3.8 \pm 1.6$ counts, which was more than that of pharmacists.

Table 3 shows the gaze time for each gaze. SPD members tended to gaze for a longer period of time on "medicines" and "picking list". Furthermore, the total gaze time for "shelf location" and "total dose" was $1.3 \pm 0.4$ (sec); thus, a longer gaze time compared to that of pharmacists.

In addition, the pharmacist tended to confirm "prescriptions" several times, when compared to the SPD member.

\subsubsection{Changes in Pupil Diameter}

Figure 3 and Figure 4 show the rate of change of pupil diameter for pharmacists and SPD members, respectively. The rates of change of pupil diameter of "picking" were $3.0 \% \pm 1.2 \%$ and $1.7 \% \pm 1.4 \%$ for pharmacists and SPD members. Conversely, of "looking at shelves," the rates were $0.1 \% \pm 0.8 \%$ and $-1.9 \% \pm$ $1.4 \%$ for pharmacists and SPD members. In both cases, the rate of change in the pupil diameter tended to be greater in pharmacists, than in the SPD members. The rate of change of pupil diameter of "putting medicines in the inner bag" was $0.1 \% \pm 2.9 \%$ and $1.0 \% \pm 2.2 \%$ for pharmacists and SPD members. The rate of change of pupil diameter tended to be greater in SPD members than pharmacists.

\section{Discussion}

In this research, we tracked pharmacists' and SPD members' gazes and examined the factors that led to their dispensing errors. Moreover, we also considered measures against human error. 


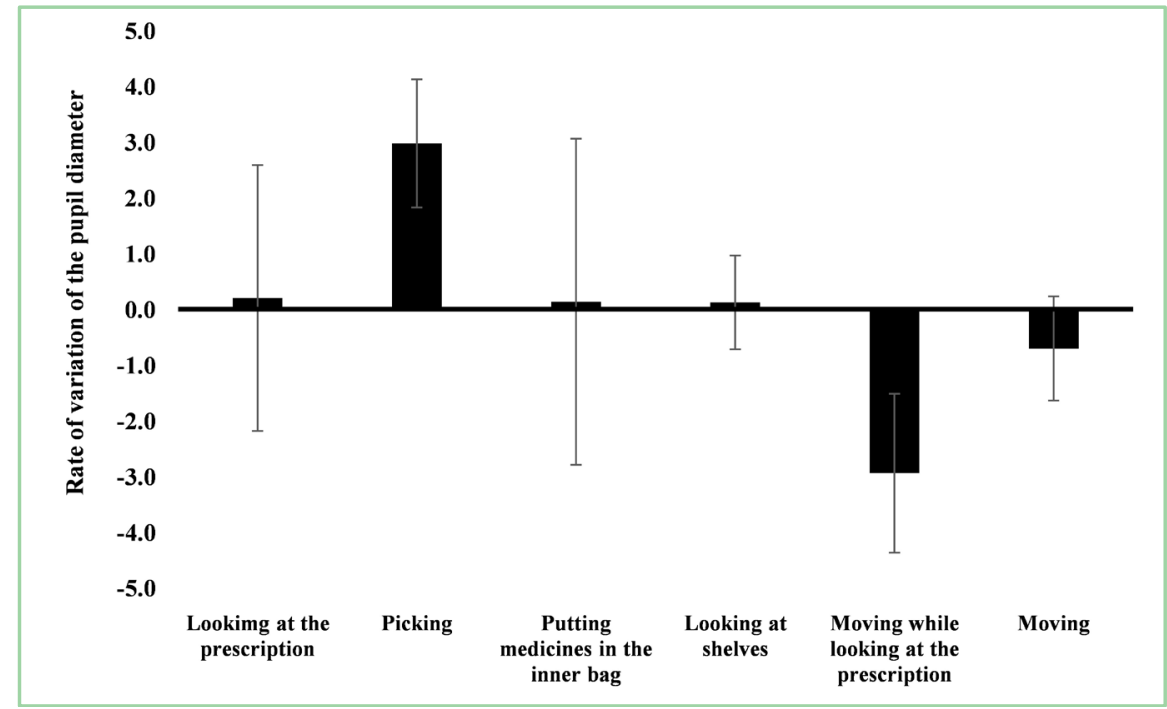

Figure 3. The rate of change of pupil diameter for pharmacists. $(n=4-5)$.

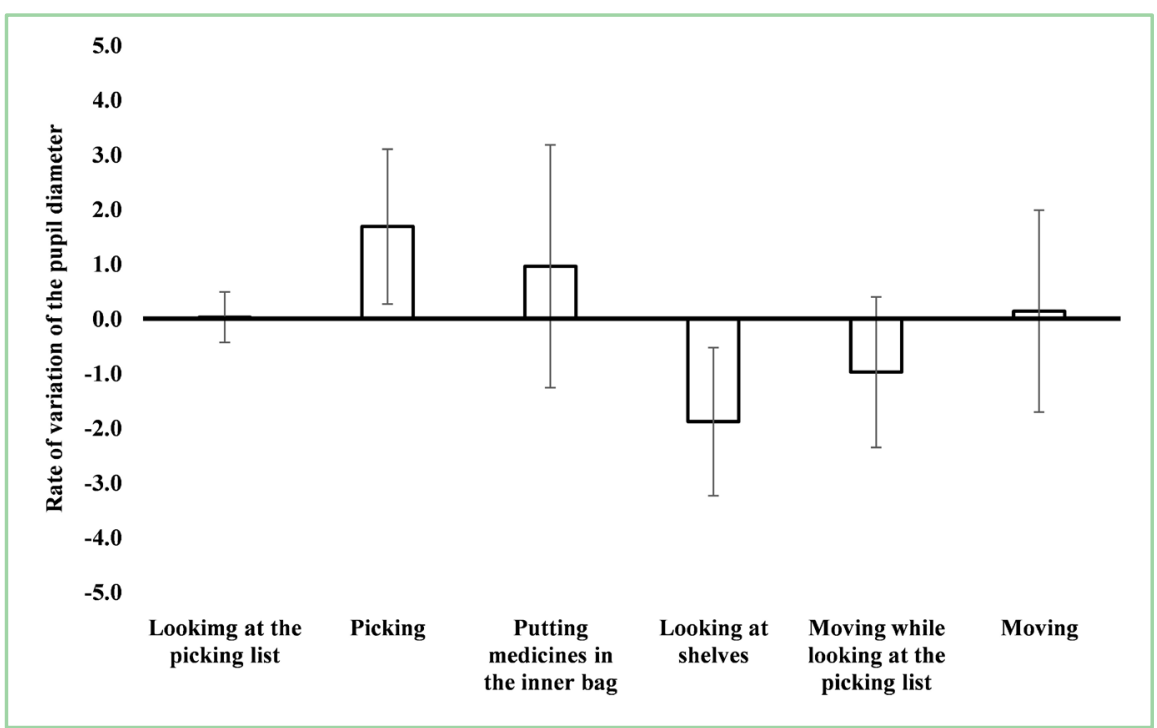

Figure 4. The rate of change of pupil diameter for SPD members $(n=4-5)$.

Table 1. Gaze ratio (\%) $(\mathrm{n}=4-5)$.

\begin{tabular}{|c|c|c|c|c|c|c|c|c|}
\hline \multirow{4}{*}{ Pharmacist } & & \multirow[b]{2}{*}{ Shelf } & \multirow[b]{2}{*}{ Medicine } & \multicolumn{4}{|c|}{ Prescription } & \multirow[b]{2}{*}{ Other } \\
\hline & & & & Total & $\begin{array}{c}\text { Patient } \\
\text { background }\end{array}$ & $\begin{array}{l}\text { Drug name, } \\
\text { Administration } \\
\text { and dosage }\end{array}$ & $\begin{array}{l}\text { Total dose, } \\
\text { Shelf } \\
\text { location }\end{array}$ & \\
\hline & Ave & 12.8 & 44.0 & 28.8 & 1.8 & 15.5 & 11.6 & 14.4 \\
\hline & $\mathrm{SD}$ & 8.3 & 15.1 & 11.2 & 5.0 & 7.9 & 4.9 & 9.4 \\
\hline \multirow{4}{*}{ SPD } & & \multirow{2}{*}{ Shelf } & \multirow{2}{*}{ Medicine } & \multicolumn{4}{|c|}{ Picking list } & \multirow{2}{*}{ Other } \\
\hline & & & & Total & Shelf location & Drug name & Total dose & \\
\hline & Ave & 7.9 & 45.6 & 24.3 & 7.1 & 11.2 & 6.0 & 22.1 \\
\hline & SD & 3.6 & 10.9 & 11.4 & 4.3 & 7.0 & 4.3 & 10.3 \\
\hline
\end{tabular}


Table 2. The number of gaze events per drug $(n=4-5)$.

\begin{tabular}{|c|c|c|c|c|c|c|c|c|}
\hline \multirow{4}{*}{ Pharmacist } & & \multirow[b]{2}{*}{ Shelf } & \multirow[b]{2}{*}{ Medicine } & \multicolumn{4}{|c|}{ Prescription } & \multirow[b]{2}{*}{ Other } \\
\hline & & & & Total & $\begin{array}{c}\text { Patient } \\
\text { background }\end{array}$ & $\begin{array}{l}\text { Drug name, } \\
\text { Administration } \\
\text { and dosage }\end{array}$ & $\begin{array}{l}\text { Total dose, } \\
\text { Shelf } \\
\text { location }\end{array}$ & \\
\hline & Ave & 1.3 & 2.7 & 5.8 & 0.2 & 3.0 & 2.6 & 1.8 \\
\hline & SD & 0.4 & 1.4 & 2.2 & 0.3 & 1.3 & 1.1 & 1.1 \\
\hline \multirow{4}{*}{ SPD } & & & & \multicolumn{4}{|c|}{ Picking list } & \\
\hline & & & & Total & Shelf location & Drug name & Total dose & \\
\hline & Ave & 1.4 & 3.3 & 6.9 & 1.8 & 3.1 & 2.0 & 3.2 \\
\hline & $\mathrm{SD}$ & 0.4 & 1.1 & 2.5 & 0.8 & 1.3 & 1.1 & 1.4 \\
\hline
\end{tabular}

Table 3. The gaze time (sec). $(n=4-5)$.

\begin{tabular}{|c|c|c|c|c|c|c|c|c|}
\hline \multirow{4}{*}{ Pharmacist } & & \multirow[b]{2}{*}{ Shelf } & \multirow[b]{2}{*}{ Medicine } & \multicolumn{4}{|c|}{ Prescription } & \multirow[b]{2}{*}{ Other } \\
\hline & & & & Total & $\begin{array}{c}\text { Patient } \\
\text { background }\end{array}$ & $\begin{array}{l}\text { Drug name, } \\
\text { Administration } \\
\text { and dosage }\end{array}$ & $\begin{array}{l}\text { Total dose, } \\
\text { Shelf } \\
\text { location }\end{array}$ & \\
\hline & Ave & 1.3 & 2.6 & 1.8 & 0.7 & 0.7 & 0.7 & 1.1 \\
\hline & $\mathrm{SD}$ & 0.5 & 1.4 & 0.9 & 0.9 & 0.3 & 0.2 & 0.8 \\
\hline \multirow{4}{*}{ SPD } & & \multirow{2}{*}{ Shelf } & \multirow{2}{*}{ Medicine } & \multicolumn{4}{|c|}{ Picking list } & \multirow{2}{*}{ Other } \\
\hline & & & & Total & Shelf location & Drug name & Total dose & \\
\hline & Ave & 1.1 & 3.0 & 3.0 & 0.7 & 0.7 & 0.6 & 1.4 \\
\hline & SD & 0.4 & 1.4 & 0.5 & 0.3 & 0.2 & 0.3 & 0.6 \\
\hline
\end{tabular}

In the results of the eye tracking, we observed that pharmacists spent the most time gazing on "prescriptions," while SPD members spent the most time gazing on "shelf location" and "total dose". These results are suggested to be due to SPD members picking medicines by reading the picking list that only displays "shelf location" "medicine name", and "total dose." Pharmacists, on the other hand, check the patient information, intention of the prescription, and contents of the prescription and so on, when picking medicines. The gaze rate on "shelf" was greater for pharmacists than SPD members. It is thought that pharmacists have to look at the similar name medicines and different dosage medicines. However, SPD members have been picking medicines by checking only "shelf location", "medicine name" and "total dose" on the picking list. SPD members tended to spend a greater number of gaze time and gaze counts, on "medicines" and "picking list," than pharmacists. The SPD members were checking each medicine at the time of picking, furthermore, were working indifferently. Pharmacists performed various work operations in parallel, such as checking the prescription and looking the next shelf location, at the time of picking. However, this is thought to be a factor linked to careless mistakes. Pharmacists with a longer experience in the field, have different gaze locations and work content, compared 
to less experienced pharmacists. They are also reported to make more mistakes due to assumptions [11]. Similar to these reports, the fact that pharmacist subjects had longer experience in the field and different gaze locations and work content than SPD members, suggests a possible factor affecting dispensing errors made by pharmacists.

Based on the results of the changes in pupil diameter, pharmacists showed the tendency to have larger pupil diameters at "looking at shelves" and "picking", than SPD members, like the result of eye tracking. It is thought that the above actions serve as the reasons why their concern and interest in "looking at shelves" have increased, and their pupil diameter has also relatively increased. The pupil diameter at "putting medicines in the inner bag" tended to be larger for SPD members than for pharmacists. Many SPD members rechecked the medicine name and quantities when placing the medicines in inner bags, which is thought to be the cause of their increased pupil diameter.

In this research, the items showing changes in results differed between pharmacists and SPD members. However, the gaze rate for "medicines" was approximately $45 \%$ and equal between the two subject groups. Additionally, both groups had the greatest pupil diameter at "picking." It was conjectured that SPD members had more clearly defined items to check when picking, compared to pharmacists. This may have possibly led to a lower chance of dispensing errors being introduced by SPD members. This result is consistent with the results of the investigation concerning error events. It is thought that SPD members and the automatic dispensing system would make fewer mistakes than pharmacists when performing a picking, which would lead to a decrease in dispensing errors. However, when SPD members become well-versed in the picking process, they may conceivably picking medicines without checking the shelf locations on the picking list. This would then result in similar errors made by pharmacists. Maintaining the flow when checking "shelf location" to "picking" is also thought to be important, these results suggest that gazing on several items while performing a picking by pharmacist are most closely linked to mistakes by attention loose. Accordingly, if pharmacists adapt prescription inspection prior to the picking process, such mistake may be averted. In the future, as well as the picking, it is necessary to investigate factors concerning medical incidents prevention in various viewpoints, such as powders dispensing, injections dispensing, the medicine inspection and so on.

Across the entire Department of Pharmacy, Aichi Medical University, 3 - 6 medical incidents occur each year, while 15 - 20 dispensing errors occur each month. Although human error cannot be completely eradicated, the importance of inspecting is once again recognized, as some picking mistakes occurred where patients were handed the wrong medicine (despite approximately $3.3 \%$ being prevented at medicine inspection). Furthermore, these results suggest that the process of picking is not a mandatory requirement of pharmacists during the action of dispensing. Instead, SPD members, pharmacy assistants, or automatic dispensing devices and the like, could serve as substitutes for this operation. It is 
suggested that pharmacists should spend more time and effort on prescription inspection, medicines checking and dosing operations.

\section{Acknowledgements}

We would like to thank the pharmacy staff of the Department of Pharmacy, Aichi Medical University Hospital who cooperated in this study.

\section{Conflicts of Interest}

The authors declare no conflicts of interest regarding the publication of this paper.

\section{References}

[1] Japan Council for Quality Health Care Division of Adverse Event Prevention (2017) Project to Collect Medical Near-Miss/Adverse Event Information 2016 Annual Report August 28, 2017.

[2] Kanzaki, H., Nishihara, S., Murakawa, K., Kitamura, Y. and Sendo, Y. (2017) byouin ni okeru yakuzaishigyoumu to iryouannzenntaisaku $\sim$ dejitarutu-ru wo mochiita chouzaimisu no boushi. Medicine and Medicine Journal, 53, 125-130. (In Japanese)

[3] Kawano, R. (2018) Era ni taisuru mikata kanngaekata wo kaeru! Hyumanera ha geiinn dehanaku kekka dearu. Journal of the Japan Pharmaceutical Association, 70, 19-24. (In Japanese)

[4] Ministry of Health, Labour and Welfare (2012) Medical Service Fee Revision in FY2012.

https://www.mhlw.go.jp/stf/seisakunitsuite/bunya/kenkou_iryou/iryouhoken/iryou hoken15/

[5] Nakagawa, Y., Uramoto, K., Kozono, A., Shiota, K., Akamine, C., Yamabe, M., et al. (2015) The Increase in the Inquiries and the Superior Examply by Inpatient Pharmaceutical Service: Second Report. Japanese journal of Natinal Medical Services, 69, 530-533.

[6] Ito, S., Kato, T., Kawai, K., Ito, K., Isogai, S., Akita, T., et al. (2004) Pharmaceutical Management and Consulting Service as an Important Factor in Malplactice Prevention. Journal of Japanese Society of Hospital Pharmacists, 40, 49-52.

[7] Japan SPD Association (2009) About SPD. https://www.mhlw.go.jp/shingi/2009/02/dl/s0213-12c_0001.pdf

[8] Ministry of Health, Labour and Welfare (2012) SPD. https://www.mhlw.go.jp/shingi/2002/07/s0726-9c.html

[9] Noma, K. and Ogawa, K. (2010) Measurement System of Pupillary Responses for E-Learning Support System. IPSJ SIG Technical Report, CLE-2 (3).

[10] Hara, N. (2012) Pupillographic Stres, Arousal and Emotion Assessments in Visual Stress. Japanese Journal of Visual Science, 33, 47-51.

[11] Oshima, T., Kato, A., Saito, S., Uchida, M., Maeda, S., Onishi, M., et al. (2011) Study on Factor Analysis on Medical Error (1) Influence of Experience of the Pharmacist to Dispensing. Journal of Ergonomics in Occupational Safety and Health, 12, 1-7. 